\title{
A Mini Review: Visual and Auditory Perception in Dyslexia
}

\author{
Ali S. A. ${ }^{a}$, Reza F. ${ }^{a}$, Fadzil N. A. ${ }^{\mathrm{b}}$, Mustafar F. ${ }^{\mathrm{a}}$, Begum T. ${ }^{\mathrm{a}}$ \\ ${ }^{a}$ Department of Neurosciences, School of Medical Sciences, Universiti Sains Malaysia \\ ${ }^{b}$ Department of Psychiatry, School of Medical Sciences, Universiti Sains Malaysia
}

\author{
Keywords \\ dyslexia, perception, auditory, visual, audio \\ -visual \\ Corresponding Author \\ Siti Atiyah Ali \\ Department of Neurosciences, School of \\ Medical Sciences, Universiti Sains \\ Malaysia, Kubang Kerian, Kota Bharu, \\ Kelantan, Malaysia. \\ Tel No: +6-013-3153685 \\ E-mail: atiyahali90@yahoo.com.my \\ Received: 12 August 2020; Accepted: 8 \\ March 2021 \\ Doi: https://doi.org/10.31436/imjm.v20i4
}

\begin{abstract}
Dyslexia is a reading disorder defined as the consequences of sensory impairment which can be quite tricky in diagnosis, as many symptoms of dyslexia tend to overlap with learning disabilities such as Specific Language Impairment (SLI), dysgraphia, dyscalculia, and a few others. However, as research keeps on progressing, a consensus has been made suggesting that dyslexia is commonly attributed to the impairment of auditory and visual perception. This review paper intends to discuss the detailed progression of research focusing on auditory and visual perception among dyslexics.
\end{abstract}

\section{INTRODUCTION}

Dyslexia is an impairment of reading ability described as defects in the development of reading skills. ${ }^{1}$ This low literacy among dyslexics is caused by the inability to coordinate visual placement, poor sequencing, and leftright confusion, with all three symptoms arising from neurological impairment or syndromes. 2,3 The etiology of dyslexia is still debated, some say it is caused by impairment of visual, auditory, and even mental development, while others disagree. In 1968, the World Federation of Neurology established an official definition of dyslexia by describing it as "a disorder manifested by difficulty in learning to read despite conventional instruction, adequate intelligence, and socio-cultural opportunity. It is dependent upon fundamental cognitive disabilities which are frequently of constitutional origin". ${ }^{4}$ The difficulty faced by a dyslexic individual emerges in the ability to associate the sound of words (phonemes) with the letters that they see. This is known as a phonological deficit in grapheme -phonemic decoding whereby they struggle with fluent reading and undertake laborious effort. It is even more difficult when the orthographic system has no irregular spelling-to-sound correspondence such as in the English language. ${ }^{5}$ However, even though the irregularity of phonemic systems is one of the factors in dyslexia, it has been determined that the impairment of visual-spatial and auditory perception may also interfere with phonological development processing.

Sensory integration and sensory function are the two components needed for the cognitive and executive functions development. Stein (2018) pioneered the study of magnocellular visual impaired function in dyslexia instead of the well-known opinion in phonological weakness. Stein argued that developmental dyslexia is characterised by poor temporal processing which interferes with the sequencing of visual and auditory input and these could be a result of impaired development in the magnocellular cellular pathway in the visual brain system. ${ }^{3}$ The magnocellular theory does not only limited to temporal processing deficit, but it eventually affects the cognitive function in processing sensory input as seen in impaired covert shifted attention, attentional shifting, divided attention among 
dyslexics in which according to Facoetti et al., (2003), the causal link of deficit in sensory cognitive function is triggered by magnocellular impairments. ${ }^{6}$ Another explanation supporting these arguments might be related to dysfunction of rapid neural adaption among dyslexics (see Perrachione et.al, 2016).

\section{The Mechanism of Auditory Perception}

The auditory system comprises of the peripheral and nervous systems. The peripheral system is divided into the outer, middle, and inner ear. Each of the parts plays a different function in terms of acoustic amplification. In the outer part, the pinna helps in collecting sound which is then amplified by the auditory canal. Next, the sound passes through the middle ear, where the mismatched impedance of different mediums (air to fluid) takes place. The bone structures of the middle ear, which are the ossicles, malleus, and incus overcome the mismatched impedance by overcoming the air-fluid pressure by boosting the pressure, creating vibration of tympanic membrane allowing transmission of sound via mechanical energy. Overcoming the mismatched impedance is essential, as the transmission of sound energy across mediums reflects back the sound energy, causing the loss of sound intensity. ${ }^{7}$ The sound energy then travels along the basilar membrane of the cochlear creating travelling waves, allowing the amplification of sound by the outer hair cell (OHC) and leading to the transduction of electrical signals by the inner hair cell (IHC) of the Organ of Corti. ${ }^{8}$ IHC transduces in microseconds, compared to the tens to hundreds of milliseconds relative to photoreceptors and olfactory neurons. ${ }^{8}$

The ability to locate sound localization is a complement factor in betterment of auditory perception, which is being supported and processed by the neurons at cochlea nuclei $(\mathrm{CN})$ at the brainstem and lateral lemniscus (LL) and inferior collicullus (IC) at the midbrain. From there, the signal transduction will be projected to superior colliculi and optic tectum of vision, allowing the visual-audio integration in localizing sound sources. ${ }^{8}$

Figure 1 illustrates the structural basis of the auditory perception pathway starting from the outer part of the ear to the central auditory processing pathway, including the auditory cortex and higher cognitive level. Hearing is basically defined as the ability to perceive sound or acoustic stimuli (Figure 1). Human beings are able to perceive a wide range of sound frequencies $(20 \mathrm{~Hz}$ to $20 \mathrm{KHz}$ ) and a large dynamic range of intensities (0 to $120 \mathrm{~dB})$. Humans perceive the acoustic stimuli with its physical attributes such as pitching and loudness.

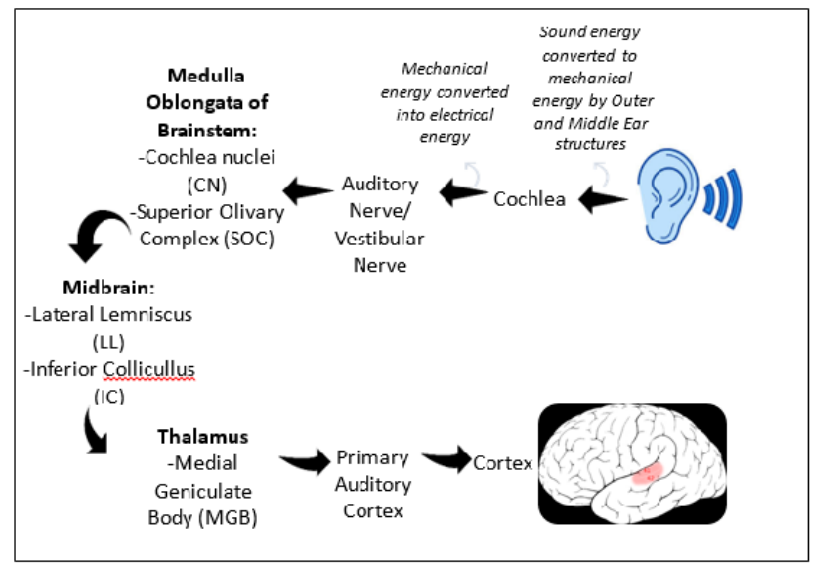

Figure 1: Figure shows the auditory perception pathway. Modified and adapted from Hernández-Zamora and Poblano (2014). ${ }^{9}$

In dyslexia, the mechanism of auditory processing is normally functioning in both peripheral and nervous stage. However, the empirical evidence in associating the development of phonological processing corresponding to visual input of reading had certain changes in the neural brain network compared to normal readers. This was based on the fMRI study by Blau et al., (2009) who found that the adult dyslexic readers had hypoactivation of brain region in letters and speech sound (forms through build-up of phonological knowledge) integration located in superior temporal cortex area. Due to that factor, the dyslexics probably faced difficulty in reading due to this fundamental deficit in processing basic phonological knowledge, hence affecting the grapheme phonemic conversion process that represents audiovisual integration as well. 10

\section{Auditory Perception Mechanism in Dyslexia}

The development of language acquisition is contributed by the well-developed auditory perception in which it provides the ability in distinguishing a variety of physical properties of sound (i.e., pitch, tones, volumes, rhythms). ${ }^{11}$ Auditory perception arises from 3 different mechanisms, which are the transduction of sound waves into electrical inputs, noise filtration, and associating sounds into recognisable bytes of memories. It was 
proposed by Gabay, Najjar and Reinisch (2019) that dyslexics are not only suffering from impairment in direct temporal processing, but also temporal perception in phonological information/input deficits. ${ }^{12,13}$ Differential consensus relates to phonological deficits in dyslexia where according to Mealings and Cameron (2019) there are two prominent theories for phonological deficits in dyslexia. The first theory is the rate-processing constraint theory which theorizes on the short processing of timescale and the second theory is the temporal sampling framework hypothesis that describes the relations of phonological deficit with longer timescale processing. However, at the end of their experiment in auditory resolutions, auditory spatial processing, and phonological awareness, they rejected all these hypotheses as the single cause of reading difficulty in dyslexia as they encountered contrasting results in their study. ${ }^{14}$

Temporal phonological processing abnormality gives a negative impact on the perception of speech sounds and phonological awareness which will eventually cause problems encoding phonemic reading. ${ }^{15}$ However, it has remained undetermined whether the abnormal processing of phonological inputs are the primary or secondary impairments affecting auditory perception among dyslexics. Another side of view proposed is that the auditory perception does developed by the multifunctional process of auditory sensory processing which includes auditory attention, discrimination, sequential temporal processing, tonal processing, auditory memory, and language processing.

In a recent research, it was discovered that the auditory perception deficit in dyslexia is highly linked to the neurocognitive attentional deficit in processing sensory stimulation that goes for visual and auditory stimulations. In the reading process, our perception in sensory processing especially auditory does not only operate visual inputs in decoding the alphabets structure orthographical structure, but also on the phonological knowledge on each of the orthographical structure, allowing for the decoding process of grapheme phonemic conversion throughout reading process.

\section{i. Auditory Attention}

For normal readers, the process of reading is naturally smooth without difficulty, but for those with reading difficulties as in dyslexia, most of them are not able to associate the orthographical structure with its phonemic sound. Due to that, they have difficulties in graphemephonemic conversion during reading. According to Pugh et al., (2013), such phonological processing in grapheme-phonemic conversion is causally affected by rapid auditory processing, which according to some evidence, links to attentional cognitive deficit in sensory processing, including attention. 16,17 Auditory attention allows for the 'tune in' sensory attention towards auditory input, allowing for the learned auditory information to be associated with reading blocks, which is lacking in dyslexics. ${ }^{18}$ Auditory attention is a part of auditory cognitive studies that is able to influence the capabilities of learning and behavioral functions. Impaired cognitive attention can be seen in hyperactivity or Attentional Deficit Hyperactivity Disorder (ADHD). ${ }^{19}$

However, in the case of dyslexia, lack of sensory attention is claimed as the cause of reading difficulty instead of behavioral problems. The lack of attention in dyslexia is an evidence by general executive function assessment provided by neuropsychological test such as in Rey auditory verbal Learning Test (RAVLT), Staggered Spondaic Word test (SSW), and Continuous Performance Test (CPT). 20,21 In electrophysiological studies of auditory processing in a group of dyslexics, it was discovered that the elicitation of certain peak in neural waveforms in Event Related Potential (ERP) tests such as N100, P200 and P300 ERP components had been attenuated in amplitudes and delayed in latencies. These ERP findings suggested on reduced neural performance in processing early onset of auditory stimulus, auditory perception and auditory attention, respectively to N100, P200 and P300 ERP components. 22 Similar findings of electrophysiological ERP studies can be seen in recent studies such as Papagiannoupoulou and Lagopoulos (2017), Halliday et al., (2014), Maciejewska et al., (2013), that being simplified in Table 1 (Table 1). ${ }^{23}$ 
Table I: Literature summary of electrophysiological ERP studies on dyslexics

\begin{tabular}{|c|c|c|c|}
\hline $\begin{array}{l}\text { Author \& Year of } \\
\text { study }\end{array}$ & $\begin{array}{l}\text { Papagiannoupoulou \& Lagopoulous } \\
\text { (2017) } 23\end{array}$ & $\begin{array}{l}\text { Halliday, Barry, Hardiman and } \\
\text { Bishop (2014) } 24\end{array}$ & $\begin{array}{l}\text { Maciejewska, Wiskirska-Woźnica } \\
\text { and Świdzińsk (2013) } 25\end{array}$ \\
\hline General aim of study & $\begin{array}{l}\text { To study topographical distribution of } \\
\text { P300 ERP component in its amplitude and } \\
\text { latency in large sample of dyslexic children. }\end{array}$ & $\begin{array}{l}\text { To compare Mismatch negativity } \\
\text { (MMN) and Late MMN (LDN) of } \\
\text { changes in auditory frequency } \\
\text { between groups of dyslexic children } \\
\text { and normal readers. }\end{array}$ & $\begin{array}{l}\text { To investigate the auditory evoked } \\
\text { potential in dyslexia. }\end{array}$ \\
\hline Methodology & $\begin{array}{l}\text { 1) P300 ERP component was studied } \\
\text { during auditory oddball paradigm among } \\
20 \text { dyslexic children and } 19 \text { normal reader } \\
\text { children. } \\
\text { 2) All children were matched in age, gender } \\
\text { and IQ (assessed with Wechsler } \\
\text { Abbreviated Scale of Intelligence, } 2^{\text {nd }} \\
\text { edition, WASI-II). }\end{array}$ & $\begin{array}{l}\text { 1) } 20 \text { dyslexic children and } 20 \\
\text { normal readers between the ages of } \\
6 \text { to } 14 \text { years old were involved. } \\
\text { 2) An ERP method using a subset } \\
\text { of auditory oddball tones consisted } \\
\text { of a standard tone }(1 \mathrm{KHz}) \text { and two } \\
\text { target tones }(1.2 \mathrm{KHz} \text { and } \\
1.03 \mathrm{KHz}) \text {. }\end{array}$ & $\begin{array}{l}\text { 1) } 55 \text { dyslexic children and } 36 \text { healthy } \\
\text { children which ranged from } 7 \text { to } 18 \\
\text { years old children were involved. } \\
\text { 2) Acoustic stimulation used to elicit } \\
\text { MMN neural response stand of speech } \\
\text { signals: syllables /ga/ as the standard } \\
\text { and /da/ as the target stimuli. } \\
\text { 3) Acoustic stimulation for P300 } \\
\text { elicitation consisted of } 1 \mathrm{KHz} \text { as the } \\
\text { standard tones and } 2 \mathrm{KHz} \text { as the target } \\
\text { tones. }\end{array}$ \\
\hline ERP Results & $\begin{array}{l}\text { - Dyslexic children had significantly } \\
\text { decreased P300 amplitudes at the central } \\
\text { brain area and prolong latencies at the } \\
\text { frontal, central and posterior brain areas. }\end{array}$ & $\begin{array}{l}\text { - No significant difference of MMN } \\
\text { amplitudes between groups. } \\
\text { - Reduced LDN amplitudes in } \\
\text { dyslexics. }\end{array}$ & $\begin{array}{l}\text { - No significant differences were } \\
\text { recorded in amplitudes MMN and P } 300 \\
\text { between groups. } \\
\text { - Both latencies of MMN and P300 } \\
\text { were significantly prolong in dyslexic } \\
\text { children }\end{array}$ \\
\hline Summary of findings & $\begin{array}{l}\text { - In general, the P300 findings in } \\
\text { amplitudes and latencies (including } \\
\text { topography) suggest on abnormality in } \\
\text { inhibitory process of attentional allocation } \\
\text { mechanism in dyslexics that signified the } \\
\text { association of reduced mental auditory } \\
\text { processing in dyslexic children. }\end{array}$ & $\begin{array}{l}\text { - Generally, the findings indicated } \\
\text { on the possibility of unimpaired } \\
\text { auditory cortical processing in } \\
\text { discrimination of auditory tones as } \\
\text { indicated by early MMN among } \\
\text { dyslexics, but rather having auditory } \\
\text { processing deficit on the late stage } \\
\text { LDN processing. }\end{array}$ & $\begin{array}{l}\text { - The ERP results was rather } \\
\text { inconclusive, however, in summary, the } \\
\text { authors highlighted that the differences } \\
\text { spotted in dyslexics could suggest on } \\
\text { impairment in processing acoustic } \\
\text { information and provide evidence in } \\
\text { heterogeneity of dyslexic population. }\end{array}$ \\
\hline
\end{tabular}

\section{i. Impaired rapid auditory processing}

Rapid auditory temporal processing is the required process for auditory and speech perception, allowing the mastery of languages for verbal communication. In the case of dyslexia, speech perception in language acquisition is not as inadequate as other learning disorders such as specific learning disability (SLD) and autism spectrum disorder (ASD), which are limited by intellectual quotient (IQ) levels and social skills. ${ }^{26}$ Dyslexics with no overlapping learning disorders commonly have equal or above average scores of IQ, suggesting the possibility of learning improvement by proper rehabilitation and teaching methods.

An abundance of theories and hypotheses were proposed to explain the physiological process of auditory sensory impairment in dyslexics, with some of the theories mentioning alterations of rapid auditory processing and cerebellar dysfunction. The theory of rapid auditory processing alteration among dyslexics was suggested by Temple et al., (2002), where they identified fMRI findings that indicated left prefrontal activity in normal readers in response to slowly changing (rapid to slow) non-linguistic acoustic stimuli. ${ }^{27}$ In contrast to that finding, there was no differential activity in response to the same acoustic stimuli. This research finding suggests that the left prefrontal regions of dyslexics were insensitive towards the difference between rapid and slow changes in acoustic stimuli, suggesting that the left prefrontal cortex is important for rapid processing, which critically functions in reading. Furthermore, they also discovered that there was a reduction in pitch discrimination performance as normal readers had better accuracy with it compared to dyslexic readers $(p<0.01)$, with more reliable accuracy for slow rather than rapid stimuli $(p<0.01) \cdot{ }^{27}$

In sum, the auditory processing in dyslexics had manifestation of altered differences of auditory processing compared to those healthy normal readers in terms of auditory attention and temporal processing. However, the cause for such alteration is yet to be determined.

\section{The Mechanism of Visual Perception}

McAnally, Castles, and Stuart have comprehensively discussed this matter in their review which they 
subdivided into two parts. The first part was structured on the evidence for sensory processing in both auditory and visual domains while the second part discussed the effects of sensory deficits. ${ }^{28}$ In the first part of their discussion on visual processing, they stated that the early sensory process visualised by a dyslexic's attention skills seems to be distinctly deficit. This indicates functional defects in the visual processing system which is comprised of magnocellular and parvocellular layers. ${ }^{2}$

The mechanism of the visual system is initiated with any visual input and the light that enters the retina. The visual input that enters the retina needs to be passed on to a population of ganglion cells that are distributed on the surface of the retina structured by $\mathrm{M}$ ganglion cells and $\mathrm{P}$ ganglion cells, which are later passed to the central visual structures (Refer figure 2). There are two major pathways in the visual system in most primates and humans, and they are known as the magnocellular and parvocellular pathways. ${ }^{7}$ Both of these pathways are responsible for the axons that leave the retina and perceive visual input (vision). ${ }^{7,29}$ Both of the pathways terminate in different layers of the lateral geniculate nucleus (LGN) in the thalamus in which $\mathrm{M}$ ganglion cells terminate in magnocellular layers on LGN while P ganglion cells terminate in parvocellular layers. LGN acts as the early site of parallel processing in the mammalian visual system. ${ }^{30}$ The main distinct characteristics of the parvocellular and magnocellular pathways in primates and humans are compared in Table II (see Table II).

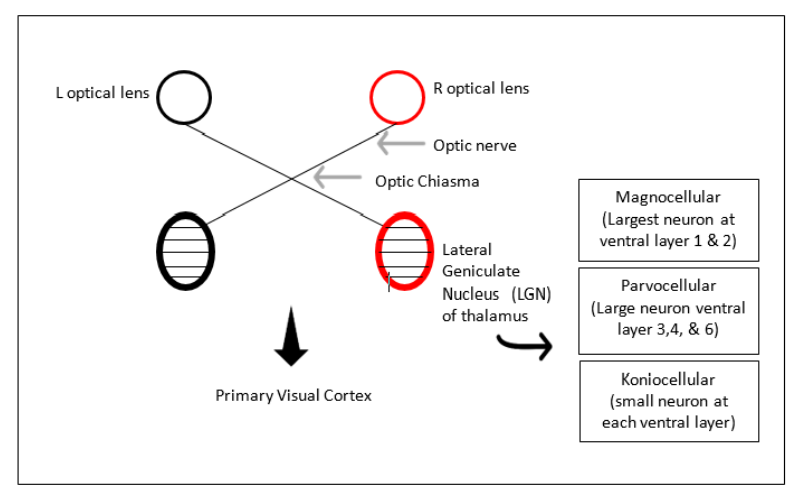

Figure 2: Figure shows the central pathway of the visual processing system. Modified/adapted from Baker (2012). ${ }^{31}$
Table II: General distinction of Magnocellular and Parvocellular Pathways

\begin{tabular}{ll}
\hline Magnocellular Pathway (M) & Parvocellular Pathway (P) \\
\hline $\begin{array}{l}\text { The M neurons have the larger cells } \\
\text { at the ventral (layer 1 \& 2) than the } \\
\text { dorsal layer. }\end{array}$ & $\begin{array}{l}\text { P layers are located on the other } \\
\text { 4 layers of LGN's ventral layer } \\
\text { (layer 3, 4, 5 \& 6) with smaller } \\
\text { sized cells than M. }\end{array}$ \\
$\begin{array}{l}\text { The M pathway has color } \\
\text { insensitivity and higher contrast } \\
\text { sensitivity. }{ }^{29}\end{array}$ & $\begin{array}{l}\text { The P pathway has high color } \\
\text { sensitivity and lower contrast } \\
\text { sensitivity. }\end{array}$ \\
$\begin{array}{l}\text { M responds towards visual } \\
\text { stimulation } 7 \text { on detection of motion }\end{array}$ & $\begin{array}{l}\text { P responds to constant visual } \\
\text { input. }\end{array}$ \\
$\begin{array}{l}\text { M is not rapid visual changes. }{ }^{30} \\
\text { color information. }\end{array}$ & $\begin{array}{l}\text { P is able to transmit } \\
\text { information on color as its } \\
\text { structure is surrounded by } \\
\text { different classes of cones. }\end{array}$ \\
$\begin{array}{l}\text { Receives projection of signals from } \\
\text { Meceives projection of signals } \\
\text { from P ganglion cells. }\end{array}$ \\
\hline
\end{tabular}

\section{Visual Perception in Dyslexia}

An overview of dyslexia research has been discussed whereby they summarised a few studies on temporal processing, processing speed, and language factors in dyslexia into a short well written review article. ${ }^{33}$ In terms of temporal processing, it was found that the domain system of the magnocellular pathway in the visual system was impaired.3,34 The magnocellular visual system crucially functions to rapidly process visual targets while reading. Without the magnocellular pathway functioning normally, the visual system is unable to perceive reading input in a rapid manner and as a consequence, dyslexics are not able to distinguish or discriminate between different temporal stimulations and tend to create a single image out of two different presentations. ${ }^{35}$ Rapid and effortless reading is linked with the Visual Word Form Area (VWFA), a specific ventral visual stream region of the brain for the recognition of letter strings. 36

Livingstone et al., (1991) conducted an experiment to search for physiological and anatomical defects in dyslexia using visual evoked potential (VEP) with different contrasts of visual stimuli presented on a checkerboard pattern among 5 dyslexics and 7 healthy subjects. The outcome revealed similar EVP results from dyslexics and the control group at 0.2 contrast 
level. However, they also found that there was a 20-40 ms delay in negative VEP wave (normal peak= around $50 \mathrm{~ms}$ ) when subjects were exposed to a lower contrast of 0.02. On another note, they also discovered the disappearance of rapidly alternating patterns of VEP at $15 \mathrm{~Hz}$ among dyslexics, but it appeared on higher alternating patterns $(>15 \mathrm{hz})$. Overall findings suggest the ability of the magnocellular system of dyslexics to respond to low contrast stimuli even though it's poorer than normal subjects and the impaired area of the magnocellular pathway was suggested to be visual area 1 or earlier. ${ }^{35}$ The impaired magnocellular system in the area of lateral geniculate nucleus (LGN) reduced their motion sensitivity which eventually caused them to have unsteady binocular fixation and effects on localization of visual perception. All of these impairments explain how dyslexics perceive each letter moving around (nonstatic) while reading. ${ }^{2}$

Based on the separate discussion of auditory and visual processing in dyslexic population, it can be postulated that the auditory and visual processing differences between dyslexics and non-dyslexics could be the sources of learning difficulty that is commonly faced by dyslexics. Despite the separate sensory findings providing different evidence of sensory impairment in dyslexia, it was found recently that the impairment of auditory and visual processing could be interfered directly and indirectly with audio-visual processing impairment. This was based on a recent study of auditory, visual and cross-modal audiovisual temporal processing in dyslexic group by Liu, Wang and Liu (2019) that found the temporal processing crossmodality stimulation contributed in development of character recognition on orthographic knowledge and phonological awareness during reading. 37 Thus, it is essential for this article to briefly review on the audiovisual perception of dyslexia as it is fundamentally developed from both auditory and visual processing.

\section{Audio-visual Perception}

A group of dyslexic adults and a group of fluent readers were compared in terms of their brain network involved in audio-visual speech perception by using slow eventrelated functional magnetic resonance imaging (fMRI) and independent component analysis. ${ }^{38}$ The test subjects were presented with a video of a female speaker conveying identical audio/visual input (congruent) and mismatched audio/visual input (incongruent). The outcome indicated less activation of the fusiform gyrus, occipital gyrus, and superior temporal sulcus among the dyslexic adult group. Russeler et al., (2018) stated that the outcome might possibly indicate poor recruitment of audiovisual processing in extracting facial information in integrating auditory and visual information. ${ }^{38}$

The presentation of the visual stimuli together with other sensory modalities such as audio, gives out a variety of effects on the sensory perception, either visual or auditory, which is also known as audio-visual integration. Enhancement of auditory perception can be seen by observing lips movements of speakers while conversing in a noisy environment which can be amplified up to $15 \mathrm{~dB}$ improvement in speech perception. 39,40 However, in the case of dyslexic readers, their integration of audio-visual stimulation was poor compared to normal readers, but the exact neural mechanisms that caused poor integration is still undetermined. Blau and his research team spent their intense focus on the neural integration of processing links between letters (visual) and speech (auditory) on dyslexic adults. The paradigm of the experimental set up was unisensory (visual or auditory) and multisensory (audiovisual congruence and audiovisual incongruence) by using fMRI. ${ }^{10}$ It was discovered that the superior temporal cortex displayed hypoactivation during the process of integrating speech sound. In other words, the audiovisual integration was poorly observed in dyslexic adults. The superior temporal gyrus was strongly reduced in response to speech sound, suggesting that there was a deficit of phonological processing in speech sound. These results do suggest that the links of predicted phonological outcome in dyslexics depends on speech processing as the audiovisual integration is critically needed for phonological processing in reading. ${ }^{10}$

Audiovisual integration was further studied by Ye et al., (2017) who conducted a study on audiovisual speech integration among German native speakers (dyslexics and fluent readers) by voicing out the numbers $0-9$ in a unimodal (visual or auditory) and congruent bimodal (visual and auditory) method and observed their brain 
response by using Functional Magnetic Resonance Imaging (fMRI). ${ }^{41}$ They observed that there was high activation of the superior temporal gyrus/sulcus when exposed to congruent bimodal stimuli compared to unimodal stimulation among fluent readers, but not among the dyslexics. Thus, these findings suggest that audio-visual integration among dyslexics was impaired due to the underperformance of superior temporal function, a phenomenon where the cause has not yet been discovered. ${ }^{41}$ However, it might be explained by the possibility of diminished neural adaptation to the audiovisual stimuli. Neural adaptation in humans can be measured by the use of fMRI in measuring the BOLD signals between blocks of repeated stimuli (to test adaptation) and non-repetitive distinct stimuli, as implied by ${ }^{42}$ Perrachione et.al (2016) who identified that there was significant reduction of auditory adaptation in phonetic-phonological correspondence of speech among adults and children with dyslexia. Reduced neural adaptation in dyslexic children especially at an early age might reduce sensitivity to language stimuli repetition prior to reading training, explaining the disability in reading among them. Besides that finding, they also observed reduction of neural adaptation in perception towards objects and faces, suggesting impairment of general capacity for short term perceptual processes. 42

Audiovisual integration can also lead to a phenomenon known as the McGurk effect which is defined as the perception that occurs when there is a simultaneous presentation of auditory acoustic input with articulatory movements (visual) corresponding to different messages (dubbing) and the outcome perceived does not correspond to the auditory input, but highly corresponds to the visual input. ${ }^{43}$ According to Bastientoniazzo et al., (2010), there were no reports of the McGurk effect among dyslexics until his study in 2010 revealed a small McGurk effect on dyslexics compared to normal readers of the same chronological age, but not to the normal readers of the same age. Even though the findings showed no significant difference across all groups, it does suggest developmental lag in audio-visual processing among dyslexics. It is a challenge for researchers to understand the nature of neural perceptual processing on sensory stimulation, particularly on how it only affects reading but no other behavioral abilities such as perceiving music, movements in dances, speech, and so on.

\section{CONCLUSION}

Studies that focused on auditory and visual perception in dyslexia enlighten our understanding on the neural pathway mechanisms that are responsible for the wide functions of cognition, including the ability to read which requires the audiovisual processing to simultaneously occurred. As demonstrated in this article, the ability to read does not only depend on unisensory visual or auditory ability, but also the integration of both forming the audio-visual perception that enables the decoding process of visual (orthographic/letters/language symbols) and phonological inputs (phonemes). The purpose of this review is to discuss the sensory perceptions that are widely accepted to be the cause of poor reading skills in dyslexia and understanding the potential causes might help us to understand how to rehabilitate and help those affected with dyslexia.

The main conclusion from this article is that the research to identify the state of visual and auditory perception in dyslexia which can lead to understanding the exact causes of poor sensory perception (auditory and visual) is still currently at the superficial level. We acknowledge that numerous researches on finding the causes of dyslexia has led to many different opinions and hypotheses. We can see from our discussions that certain brain regions in dyslexics tend to have low activations in the superior temporal gyrus/sulcus compared to non-dyslexics in response to audio-visual stimulations. ${ }^{41}$ Even so, we are still unsure on the exact mechanisms that cause the impairment, or the lack of activation of any neural mechanisms involved. Although the possible explanation is highly due to rapid adaptation theory, we are still not able to explain why all those phenomena happened. The diagnosis of sensory impairment, especially among those with dyslexia are limited, due to the presence of multiple theories regarding sensory perception such as the magnocellular theory and the phonological awareness theory. It is interesting to observe that there is still a need for studies to identify sensory perception impairment among dyslexics to determine if it is still a theory or if it 
has been scientifically proven. It is a good step for future researchers and clinicians to consider the possibility of interactions between the visual, auditory, and audio-visual perception theories,hus, enabling proper sensory management for those affected.

\section{ACKNOWLEDGEMENT}

In gratitude to Universiti Sains Malaysia RUI Grant No: 1001/PPSP/8012290.

\section{REFERENCES}

1. Dickman E. Do We Need a New Definition of Dyslexia? [Internet]. 2017 [cited 2019 May 25]. Available from: https://dyslexiaida.org/do-weneed-a-new-definition-of-dyslexia/

2. Stein J. The Magnocellular Theory of Developmental Dyslexia. Dyslexia. 2001;7:12-36.

3. Stein J. Author's Accepted Manuscript developmental dyslexia:The Current Status of The Magnocellular Theory of Developmental Dyslexia. Neuropsychologia [Internet]. 2018; Available from: https://doi.org/10.1016/ j.neuropsychologia.2018.03.022

4. Critchley M, Critchley EA. Dyslexia Defined. 1st Editio. London: William Heinemann Medical Books Ltd; 1978. 3-5 p.

5. Ziegler JC, Perry C, Ma-wyatt A. Developmental dyslexia in different languages : Language-specific or universal ? 2003;86:169-93.

6. Facoetti A, Lorusso ML, Paganoni P, Cattaneo C, Galli R, Umiltà C, et al. Auditory and visual automatic attention deficits in developmental dyslexia. Cogn Brain Res. 2003;16(2):185-91.

7. Purves D, Augustine J, Fitzpatrick DF. The Middle Ear. In: Neuroscience 2nd edition [Internet]. Sinauer Associates, Inc; 2001. Available from: https://www.ncbi.nlm.nih.gov/books/ NBK11076/

8. Hudspeth AJ, Konishi M. Auditory neuroscience: Development, transduction, and integration. PNAS. 2000;97(22):11690-1.

9. Hernández-Zamora E, Poblano A. The auditory pathway: Levels of integration of information and principal neurotransmitters. Gac Med Mex. 2014;150:447-56.
10. Blau V, van Atteveldt N, Ekkebus M, Goebel R, Blomert L. Reduced neural integration of letters and speech sounds links phonological and reading deficits in adult dyslexia. Curr Biol [Internet]. 2009;19(6):503-8. Available from: http:/ / dx.doi.org/10.1016/j.cub.2009.01.065

11. Carreiro J. Movement, perception and cognitive development. An Osteopath Approach to Child. 2009;31-45.

12. Gabay Y, Najjar I, Reinisch E. Another Temporal Processing Deficit in Individuals With Developmental Dyslexia: The Case of Normalization for Speaking Rate. J Speech Lang Hear Res. 2019;62(7):2171-84.

13. Stein J. The magnocellular theory of developmental dyslexia. In: Reading and Dyslexia. Oxford, UK: Springer International Publishing; 2018. p. 97-128.

14. Mealings K, Cameron S. Investigating Auditory Spectral and Temporal Resolution Deficits in Children with Reading Difficulties. J Am Acad Audiol. 2019;30(6):533-43.

15. Oliveira JC, Murphy CFB, Schochat E. Auditory processing in children with dyslexia :

electrophysiological and behavior evaluation. CoDAS. 2013;25(1):39-44.

16. Pugh K, Landi N, Preston J, Mencl W, Austin C, Sibley D, et al. The relationship between phonological and auditory processing and brain organization in beginning readers. Brain Lang. 2013;125(2):173-83.

17. Lewandowska M, Milner R, Ganc M, Włodarczyk E, Skarżyński H. Attention dysfunction subtypes of developmental dyslexia. Med Sci Monit. 2014;20:2256-68.

18. Ramus F, Rosen S, Dakin SC, Day BL, Castellote JM, White S, et al. Theories of developmental dyslexia: Insights from a multiple case study of dyslexic adults. Brain. 2003;126(4):841-65.

19. Karalunas SL, Hawkey E, Gustafsson H, Miller M, Langhorst M, Cordova M, et al. Overlapping and Distinct Cognitive Impairments in AttentionDeficit/Hyperactivity and Autism Spectrum Disorder without Intellectual Disability. 2019;46(8):1705-16.

20. Riccio CA, Cohen MJ, Garrison T, Smith B. Auditory processing measures : correlation with neuropsychological measures of Attention , 
memory , and behavior. Child Neuropsychol. 2015;11(4):37-41.

21. Tinius $\mathrm{T}$. The integrated visual and auditory continuous performance test as a neuropsychological measure. Arch Clin Neuropsychol. 2003;18(5):439-54.

22. Frizzo ACF. Auditory evoked potential: a proposal for further evaluation in children with learning disabilities. Front Psychol [Internet]. 2015;6 (June):1-5. Available from: http:// journal.frontiersin.org/Article/10.3389/ fpsyg.2015.00788/abstract

23. Papagiannopoulou EA, Lagopoulos J. P300 eventrelated potentials in children with dyslexia. Ann Dyslexia. 2017;67(October 2016):99-108.

24. Halliday LF, Barry JG, Hardiman MJ, Bishop DVM. Late, not early mismatch responses to changes in frequency are reduced or deviant in children with dyslexia : an event-related potential study. J Neurodev Disord. 2014;6(21):1-15.

25. Maciejewska B, Wiskirska-Woznica B, Swidzinski P, Michalak M. Assessing Auditory Processing Disorders in Children with Developmental Dyslexia Using Auditory Cognitive Event-Related Potentials. Folia Phoniatr Logop [Internet]. 2013 Feb [cited 2020 Feb 24];65(3):129-35. Available from: https://www.karger.com/Article/ FullText/354167

26. O'Brien G, Pearson J. Autism and Learning Disability. Autism. 2004;8(2):125-40.

27. Temple E, Poldrack RA, Protopapas A, Nagarajan S, Salz T, Tallal P, et al. Disruption of the neural response to rapid acoustic stimuli in dyslexia: Evidence from functional MRI. Proc Natl Acad Sci. 2002;97(25):13907-12.

28. McAnally KI, Castles a., Stuart GW. Visual and auditory processing impairments in subtypes of developmental dyslexia: A discussion. J Dev Phys Disabil. 2000;12(2):145-56.

29. Miki A, Woo JH, Liu GT, Elliott MA. Magnocellular and Parvocellular Visual Pathways Have Different Blood Oxygen Level - Dependent Signal Time Courses in Human Primary. Am J Neuroradiol. 2006;27:1628-34.

30. Denison RN, Vu AT, Yacoub E, Feinberg DA, Silver MA. Functional mapping of the magnocellular and parvocellular subdivisions of human LGN. Neuroimage. 2015;102(2):358-69.

31. Baker CI. Visual Processing in the Primate Brain. In Handbook of Psychology. In: Second Edi. 2012.

32. Derrington AM, Lenniet P. Spatial and Temporal Contrast Sensitivities Of Neurons In Lateral Geniculate Nucleus Of Macaque. J Physiol. 1984; (357):219-40.

33. Stein J. The Neurobiological basis of dyslexia. In: Handbook of Dyslexia. 1st Editio. London: SAGE Publications Asia-Pacific Pte Ltd; 2008. p. 3-92.

34. Stein J. Chapter 3: The Neurobiological Basis of Dyslexia. In: Reid G, Fawcett JA., Manis F, Siegel SL, editors. The SAGE Handbook of Dyslexia. 2008.

35. Livingstone MS, Glenn RD, Drislane FW, Galaburda AM. Physiological and Anatomical Evidence for a Magnocellular Defect in Developmental Dyslexia. Proc Natl Acad Sci. 1991;88:7943-7.

36. Boros M, Anton J, Pech-georgel C, Grainger J, Szwed M, Ziegler JC. NeuroImage Orthographic processing de fi cits in developmental dyslexia : Beyond the ventral visual stream. Neuroimage [Internet]. 2016;128:316-27. Available from: http://dx.doi.org/10.1016/ j.neuroimage.2016.01.014

37. Liu S, Wang LC, Liu D. Auditory, visual, and cross -modal temporal processing skills among chinese children with developmental dyslexia. J Learn Disabil. 2019;52(6):431-41.

38. Rüsseler J, Ye Z, Gerth I, Szycik GR, Münte TF. Audio-visual speech perception in adult readers with dyslexia: an fMRI study. Brain Imaging Behav. 2018;

39. Spence C, Soto-Faraco S. Auditory perception: Interactions with vision. Oxford Handb Audit Sci Hear. 2012;271-96.

40. Ross LA, Saint-Amour D, Leavit VM, Javit DC, Foxe JJ. Do yo see what I am saying?Exploring visual enhancement of speech comprehension in noisy environments. Cereb Cortex. 2007;17:114753.

41. Ye Z, Rüsseler J, Gerth I, Münte TF. Audiovisual speech integration in the superior temporal region is dysfunctional in dyslexia. Neuroscience [Internet]. 2017;356:1-10. Available from: http:// 
dx.doi.org/10.1016/j.neuroscience.2017.05.017

42. Perrachione TK, Del Tufo SN, Winter R, Murtagh J, Cyr A, Chang P, et al. Dysfunction of Rapid Neural Adaptation in Dyslexia. Neuron. 2016;92 (6):1383-97.

43. Bastien-toniazzo M, Stroumza A, Cavé C. AudioVisual Perception and Integration in Developmental Dyslexia: An Exploratory Study Using the McGurk Effect. Curr Psychol Lett. 2010;25(3). 